Dickinson, David L. (2004) A Comparison of Conventional, Final-Offer, and "Combined" Arbitration for Dispute Resolution, Industrial and Labor Relations Review, 57(2): pp. 288-301. (Jan. 2004) Published by Cornell University (ISSN: 0019-7939).

\title{
A Comparison of Conventional, Final-Offer, and "Combined" Arbitration for Dispute Resolution
}

\author{
David L. Dickinson
}

\begin{abstract}
Two widely used forms of arbitration are conventional arbitration, in which the arbitrator makes an unconstrained settlement choice, and final-offer arbitration, in which the arbitrator must choose between disputants' final offers. Under an innovative, as yet unused approach called "combined arbitration," if the arbitrator's notion of a fair settlement lies between the disputants' final offers, final-offer arbitration rules are used; otherwise, conventional arbitration rules are used. Theoretically, by combining the risks that the two standard forms of arbitration pose for disputants who do not voluntarily settle, combined arbitration should generate convergent final offers. The results of this controlled laboratory study show, however, that dispute rates are highest in combined arbitration and lowest in conventional arbitration. These results challenge the theoretical predictions for combined arbitration as well as claims that final offer arbitration should reduce disputes compared to conventional arbitration. The results are, however, consistent with a simple theory of disputant optimism.
\end{abstract}


This article reports the results from a laboratory test of disputant behavior under three different forms of arbitration: conventional arbitration (CA), final-offer arbitration (FOA), and an innovative procedure - as yet untried in real-world cases - called "Combined Arbitration" (CombA) that combines elements of CA and FOA. In CA, the arbitrator is free to impose any settlement, whereas the rules of FOA stipulate that the arbitrator is constrained to choose one of the disputants' final offers. FOA was originally designed to increase the uncertainty costs of arbitration and to induce more settlements, but much of the theoretical work on FOA has cast doubt on that expectation.[1]

Brams and Merrill (1986) devised the CombA procedure by combining the rules of CA and FOA in a way that generates theoretically convergent final offers.[2] The rules of CombA are simple. If the arbitrator's notion of a fair settlement lies between the disputants' final offers, then the rules of FOA are used. Otherwise, the rules of CA are used. If the CombA rules generate convergent final offers in practice, and not just in theory, then CombA offers a potential major advantage over commonly used arbitration procedures: increased voluntary settlement rates. Disputants presumably prefer voluntary settlements over arbitrated settlements, and they would also save substantial time and money by invoking arbitration less frequently.

My primary goal in this article is to examine CombA's relative effectiveness. A secondary goal is to provide additional data comparing CA and FOA. Existing research contains mixed or inconclusive reports on the effectiveness of CA versus FOA, and this debate is far from resolved.[3] As will be discussed, the comparison of CA and FOA in this paper improves on previous laboratory comparisons in several ways.

\section{MOTIVATION}

The subject of bargainer incentives under arbitration is of large and growing importance. Arbitration is currently used in such diverse areas as labor disputes, commercial contract disputes, environmental disputes, securities industry disputes, tort law reform, and lemon-law disputes. One notable indication of arbitration's increasing prevalence is the Supreme Court's recent ruling that employers can require workers to take job-related disputes to arbitration.[4] Though Internet dispute resolution started only recently with online mediation and computeraided bargaining (for example, www.SquareTrade.com, www. Cybersettle.com, and www.ClickNSettle.com), arbitration now also appears online (for example, www.intellicourt.com and www.online.rcsolution.com).

Given arbitration's importance and increasing use, it is prudent to examine which arbitration rule or procedure is most effective. That said, researchers and practitioners have noted that the effectiveness of an arbitration procedure may lie in its ability to induce negotiated settlements (see, for example, Stevens 1966). CA has been thought to "chill" bargaining, because arbitration awards were considered a compromise between disputants' final bargaining positions.[5] Though FOA rules were conceived to reduce this chilling effect, theoretical work shows that disputant final offers diverge with FOA (Farber 1980; Brams and Merrill 1983), and the empirical 
evidence is ambiguous. CombA, however, produces theoretically convergent final offers, and so disputant behavior under the innovative CombA rules merits investigation.

Some researchers have used role-playing or mock negotiation experiments to study commonly used arbitration rules (for example, Neale and Bazeman 1983; Grigsby and Bigoness 1982; Notz and Starke 1978). However, leaving the arbitrator decision-making process uncontrolled can result in confounding effects that make data interpretation difficult. Ashenfelter et al. (1992) was the first laboratory study to mechanize the arbitrator decision-making process. The authors' major innovation was the use of a fixed distribution of arbitrator settlements to simulate decisions from a pool of arbitrators in the field (for empirical support for this procedure, see Ashenfelter and Bloom 1984; Ashenfelter 1987). This innovation notwithstanding, the CA and FOA dispute rates in Ashenfelter et al. are open to alternative explanations given the way arbitrator information was provided to the experimental subjects.[6] Additional data comparing CA and FOA are therefore desirable in order to clarify our understanding of CA and FOA incentives.

Controlled examinations of commonly used and innovative arbitration procedures seem prudent. Millions of dollars in dispute are allocated each year through commonly used arbitration procedures that, in theory, are expected not to induce convergence of the disputants' bargaining positions. CombA theoretically produces convergent final offers, with the result that it should eliminate the need even to invoke the procedure. Such a result would have important implications for dispute resolution in practice. Controlled experiments offer a relatively low-cost method of generating initial data on this innovative procedure.

Laboratory experiments are well suited for isolating and studying many interesting features of bargaining environments.[7] The use of experiments to generate original data comparing the innovative CombA to CA and FOA is, in any event, necessary for an even more practical reason: to my knowledge, no one has ever used CombA, and so field data on the procedure are nonexistent. Experiments are therefore the only way to generate data on CombA, and these data are needed to shed light on how the procedure affects negotiators' incentives. The generation of initial data with small-scale experiments also avoids the risks associated with trial implementation of new arbitration procedures like CombA.

\section{FRAMEWORK}

Farber's (1980) framework for bargaining behavior, which T adopt here, incorporates the stochastic nature of arbitrator decisions into the dispute resolution process. Disputants each have a desired level of one quantifiable variable, $x$. Disputant $A$ desires a low level of $x$ such that utility to disputant $A$ is $\mathrm{Ua}(\mathrm{x})=-\mathrm{x}$ (or some parametric shift of this), while disputant $\mathrm{B}$ desires a high level of $x$ such that $U b(x)=x$. Assuming that disputants cannot perfectly forecast the arbitrator's notion of a fair settlement for $x$ in any given case, their common estimate of the arbitrator's notion of a fair settlement is modeled as a density function $f(z)$. Empirical research (Ashenfelter and Bloom 1984; Ashenfelter 1987) is consistent with the notion that arbitrators are statistically exchangeable in the limit, and so the function $\mathrm{f}(\mathrm{z})$ allows the complete description of 
arbitrator behavior in theory and the mechanization of arbitrator behavior for the experimental environment.

This framework is potentially limiting given that it views all negotiations as win-loss bargaining. Bargaining theorists have noted, however, that even if bargaining contains other components of interest (attempts to manipulate attitudes, for example; or the potential for creative solutions that might be classified as win-win or integrative bargaining), a zero-sum or distributive component of the negotiations still likely exists in more complicated negotiations (see Walton and McKersie 1965). This research is then most relevant to understanding disputant behavior in more traditional distributive bargaining environments. Nevertheless, one can also consider integrative bargaining over different points on the pareto efficient frontier as a type of distributive bargaining, which expands the relevancy of this framework.

Though the convergence result of CombA is attractive, in order to predict dispute rates one needs a more explicit theory of disputes or settlements - not a theory of final offers. Consider that bargainers will dispute more frequently as the expected payoff from the arbitration procedure rises. In other words, disputing and voluntarily settling are just alternative ways of achieving an "outcome," and lower-cost (that is, higher expected payoff) alternatives will be used more frequently - a down-ward-sloping demand curve for disputes. Given the structure of CA, FOA, and CombA, it is apparent that for risk neutral disputants with unbiased expectations of $f(z)$ the expected value of the arbitrated outcome is the same across procedures.

Consequently, this expected payoff approach to predicting dispute rates generates a prediction of equal dispute rates across procedures unless disputants are not risk neutral, are biased in their expectations of $f(z)$, or both. Risk aversion and optimism are the two violations of these assumptions that are most prominently featured in the literature.

The original idea behind the suggestion that FOA would increase voluntary settlements over CA is that FOA eliminates the "middle" of the arbitrator settlement distribution, thereby increasing uncertainty relative to $C A$, so that risk-averse disputants will have lower disputes in FOA than in CA. It has been noted that FOA also decreases, uncertainty by eliminating the tails of the distribution (Farber and Bazerman 1989). Perhaps herein lies the reason for the continued debate as to whether FOA will produce higher or lower dispute rates than CA. CombA increases uncertainty both by eliminating the center of the distribution and by preserving the possibility of extreme outcomes in the tails of the arbitrator settlement distribution. Therefore, if we assume risk aversion, our ex ante hypothesis is that dispute rates in CombBA will be lowest using this expected payoff criterion. Consideration of optimism will be treated more extensively below, but suffice it to say at this point that optimism can, depending on its level, counteract or even outweigh the effects of risk aversion.

\section{EXPERIMENTAL ENVIRONMENT}

The construction of the experimental environment follows Ashenfelter et al. (1992). Pairs of subjects are matched randomly and anonymously, and each pair bargains over the value of a variable, $x$, in 20 two-minute rounds. 8 Subjects are aware of being matched with the same 
individual for the duration of the experiment. Disputant $A$ is given a payoff sheet that shows cash experimental earnings linearly decreasing in $\mathrm{x}$, whereas disputant $\mathrm{B}$ 's, payoffs linearly increase in $x$. The "pie" over which the disputants bargain in each round is a $\$ 2.00$ pie that would be equally split at $x=500$. The payoff function (in dollars) implicit in the payoff sheet is $\pi A=1.00+.005(500-x)$ for disputant $A$ and $\pi<s u b>b</$ sub $>=1+.005(x-500)$ for disputant $B$, which highlights that each one-unit change in $x$ increases or decreases disputant payoffs by one-half cent.

Subjects are aware that bargaining is win-loss in nature, but payoff levels are private information to simulate the real world asymmetry that exists in assessing the value that one's bargaining counterpart may place on the object of negotiations. Additionally, subjects are privately given suggested bargaining ranges of $x e[200,700]$ and $x \in[300,800]$ for disputant $A$ and $B$, respectively. The reason is twofold. First, this detail is meant to improve the external validity of the data generated, since realworld bargainers would likely not have full information on their counterparts' target bargaining range. Further, the asymmetric bargaining ranges help avoid rule-of-thumb outcomes of a simple 50-50 split of the "pie."[ 9] Subjects are reminded that their counterpart's bargaining range may not be the same as their own, and payoffs were not truncated at zero in the event that subjects agree to values of $x$ outside of their bargaining range (for example, if disputant $A$ agrees to $x=800$, then disputant $A(B)$ receives $\$-.50(\$ 2.50)$ for that round). Communication is not allowed during the experiment other than in the form of the numeric offers and acceptances transmitted through the subjects' computer terminals (that is, no talking or nonverbal communication is permitted, and the computer application does not allow text messages).

Subjects proceed through on-screen instructions that explain in detail all aspects of the experimental bargaining environment.[10] In this environment, disputants are free to exchange numeric offers of $x$ any way they desire. There is no stipulation that offers must "improve" upon previous offers or wait for counteroffers. The standing (most recent) offer of either disputant is displayed at the top of the offer queue, and either disputant can accept his or her counterpart's standing offer. The subjects are shown sample bargaining screens in the general instructions to highlight these important details.

Upon finishing general instructions, the subjects proceed through instructions specific to the dispute resolution procedure that is used for the rounds that follow in the event of no agreement. In naturally occurring environments, bargaining impasse still occurs even when the (certain) monetary costs are high. Arbitration's primary disagreement costs are often in terms of uncertainty (as noted by Farber and Katz 1979), whereas strikes and lockouts, for example, produce more certain monetary costs of disagreement. For this reason, I include a no-arbitration (NA) treatment in which disagreement generates a payoff of zero to both disputants for that round. Unlike in Ashenfelter et al., each bargaining pair completes 5 consecutive rounds under each of 4 dispute resolution procedures - CA, FOA, CombA, and NA. Subjects only learn of the rules to a particular dispute resolution procedure through on-screen instructions that appear immediately prior to a new set of rounds.[11] 
In the arbitration treatments subjects are given information about the nature of the arbitrator decision-making process by means of a table of 100 numbers. The table is generated from the same distribution that describes the arbitrator's notion of a fair settlement. In all arbitration treatments, this distribution is a normal distribution with mean = 500 and standard deviation = 60. Though our dispute rate predictions are based on expected payoffs, the Nash final offer predictions are still of interest - this parameterization generates predicted (risk-neutral) final offers under FOA of $x[\mathrm{sub}]=425$ and $x[\mathrm{sub}]=575$, whereas under CombA final offers are predicted to converge to $x a=x b=500$. Subjects are informed that these numbers are the last 100 draws from the same distribution that would be used in the experiment to determine settlements; this procedure allows subjects to form expectations as they would in the field. $<$ sup $>12</$ sup $>$ If bargaining impasse occurs, then the specific rules for that treatment are used to determine the outcome for that round. The instructions and experiment screen contain only context-neutral language (excluding, for example, words like dispute, arbitration, and union).

A key feature distinguishing this design from Ashenfelter et al.'s is its provision of information about the arbitrator decisionmaking process that is identical across treatmerits. Ashenfelterel al. (1992) altered the way in which the information was provided to the subjects across arbitration treatments (see note 6). While their reasoning is not without merit - their purpose was to mimic the way in which disputants might gather information about arbitrator decisions from field data - the result is an uncontrolled variable in the design that might be responsible for some of the data generation process. The design I present controls expectations formation across treatments, since arbitrator information is always given by means of a table of 100 draws from the preferred settlement distribution. Quite apart from the methodological advantages of that procedure, moreover, is a practical necessity: if these trials are to simulate how subjects might gather information on arbitrator decisions from field data, imputed data are unavoidable, since no field data exist on CombA.

Experimental data generation is not without its drawbacks. The "no-communication "experiment that I have described may seem quite distant from the spirit of realworld negotiations. However, face-to-face communication would entail a loss of control over the environment, as outcomes might be generated, in part, by "uncontrolled aspects of social interaction" (see Roth 1995). Demographic variables can be used to control for many measurable differences in the bargaining pairs, but it would be difficult to quantify and control for items such as body language. I do not claim that such items are not of interest, but the point of this study is to conduct a controlled test of behavior under three different forms of arbitration. As such, it is better to remove these items from consideration altogether.

The external validity of experimental data is also a concern. As Bolton and Katok (1998) noted, however, simple lab negotiations have captured many important features of field negotiations. The experiments reported here involve real subjects making real decisions with real cash consequences. In this case, experiments are a cost-effective way to gather data on new procedures, and they are more focused than would be a trial and error approach to discovering which procedure may work best in the field.[13] 
Table 1. Average Dispute Rates.

(Standard Errors of Means in Parentheses)

\begin{tabular}{llll}
\hline NA & CA & FOA & CombA \\
\hline .21 & .49 & .57 & .60 \\
$(.049)$ & $(.053)$ & $(.049)$ & $(.031)$ \\
Paired comparisons of dispute rates and significance: & & \\
NA $<\mathrm{CA}^{* * *}$ & $\mathrm{NA}<\mathrm{CombA} * * *$ & $\mathrm{CA}<\mathrm{CombA} * * *$ \\
$\mathrm{NA}<\mathrm{FOA} * * *$ & $\mathrm{CA}<\mathrm{FOA}$ & $\mathrm{FOA}<\mathrm{CombA}$ \\
\hline
\end{tabular}

Dispute rates are calculated for each bargaining pair in a given treatment. Averages reported are across all 48 bargaining pairs. Paired comparisons are tested using two-sample t-tests. Significance is for a one-tailed test of the mean dispute rates: "statistically significant at the .10 level; **at the .05 level; ***at the .01 level.

\section{RESULTS}

The results reported are from 48 student bargaining pairs who completed this 20-round experiment.[ 14] Subjects received an average payoff of $\$ 18.92$ ( $\Sigma=\$ 3.34$ ) for participation in the experiment, which lasted about 1 hour and 15 minutes for the average bargaining pair. Average dispute rates are reported in Table 1 along with t-test comparisons of dispute rates across pairs of procedures. Figure 1 shows the average dispute rate results for the different rounds within each treatment, averaged across all bargaining pairs (for example, round 1 in Figure 1 refers to the first round of bargaining in that particular treatment).

Figure 1. Average Dispute Rates.

(Averaged across 48 Bargaining Pairs)

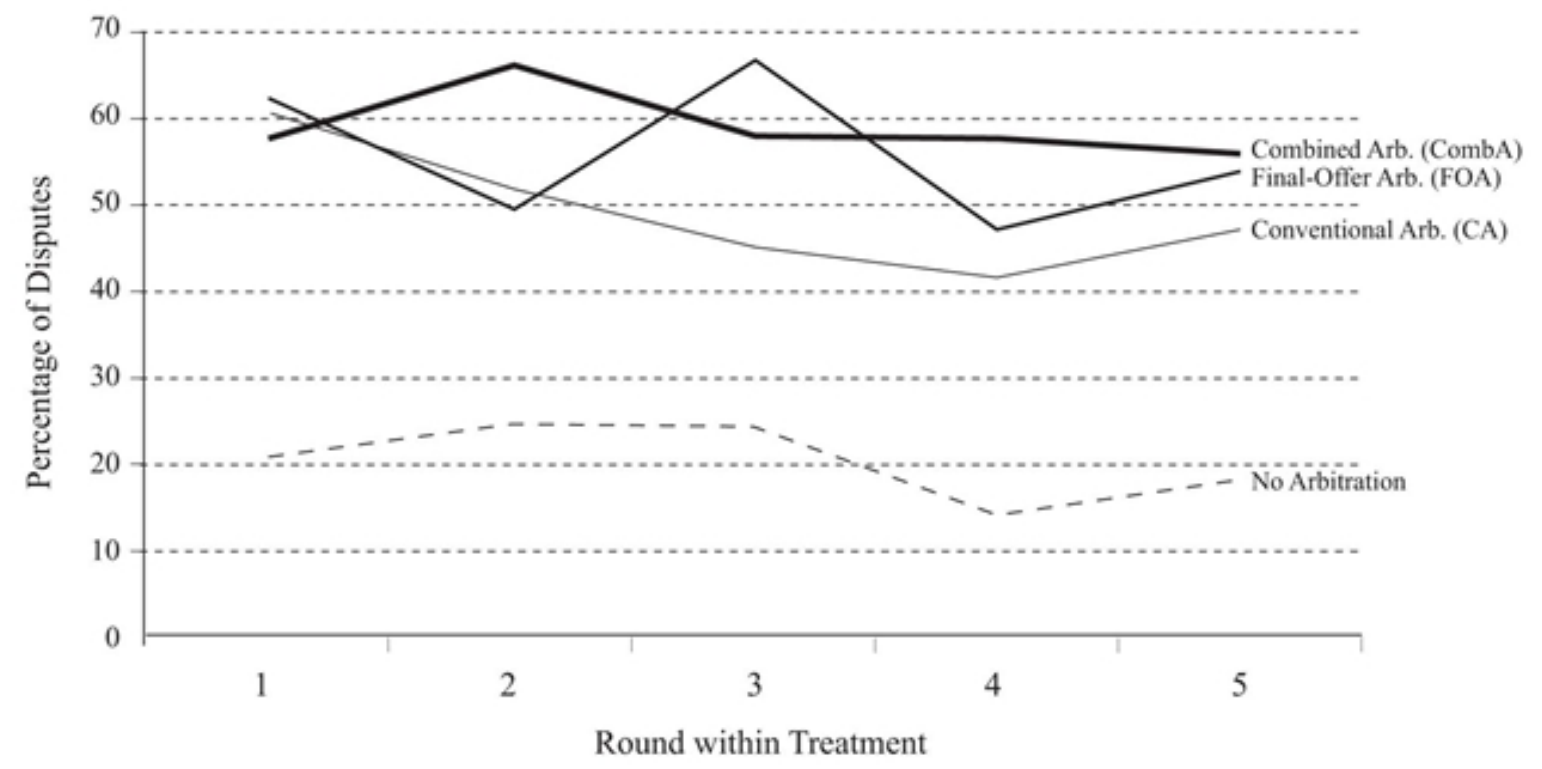

Two patterns are evident from the aggregate data. First, disputants disagree more when arbitration is used than when the disputed "pie" is destroyed in the event of disagreement. This 
replicates a basic finding of other studies that arbitration, by effectively lowering the overall cost of disagreement, increases the incidence of disagreement (for example, Currie and McConnell 1991; Ashenfelter et al. 1992; Bolton and Katok 1998; Dickinson 2001). We also see that disputes are less frequent in CA than in CombA or FOA. In comparisons using two-sample ttests (see Table 1), the difference in dispute rates between CA and CombA is statistically significant, and the difference between CA to FOA falls just short of conventionally defined statistical significance $(p=.13)$.

The results of regression-based analysis, shown in Table 2, can shed additional light on the comparative effectiveness of the different dispute resolution procedures. For this analysis, I define a dispute as an instance in which either the pie is destroyed or arbitration is invoked. Table 2 shows the results of random effects estimation of the probability of dispute, Dispute. Results in the left-hand column are from estimating a basic model of the treatment effects. The right-hand column includes a measure of conflict history (how many of the pair's previous rounds ended in dispute), a measure of overall bargaining history (Round), and a series of pairspecific variables meant to capture different dimensions of the composition of each bargaining pair. The Dispute model estimations in Table 2 account for both the interpair heterogeneity in the data and potential non-independence of the data across rounds (but within a bargaining pair).[15]

The probit equation estimates in Table 2 show that each arbitration treatment is associated with a statistically significant increase in the probability of a dispute compared to the no arbitration treatment. Further, dispute rates are actually highest in CombA, though the coefficient on CombA is not statistically significantly greater than the coefficient on FOA ( $p>.35$ for both $x 21$ [Wald] test statistics on the Table 2 models). CA increases dispute rates over NA by an amount that is statistically significantly less than the increase in dispute rates under FOA and under CombA.[16] As in Table 1, we see that dispute rates are higher with arbitration than without it. However, the relative effectiveness of the various arbitration procedures in reducing disputes is not consistent with risk neutrality and unbiased expectations and is opposite of what we would predict with risk-averse but unbiased subjects.

In short, these results are not supportive of theoretical predictions for CombA or the usual arguments about FOA reducing the "chilling" effect versus CA. I next offer a simple theory of disputant optimism that may shed some light on these results. 
Table 2. Comparative Effectiveness of Dispute

Resolution Procedures: Random Effects Probit Model Estimates.

\begin{tabular}{|c|c|c|c|}
\hline \multirow{2}{*}{$\frac{\text { Independent Variable }}{\text { Constant }}$} & \multicolumn{3}{|c|}{$\begin{array}{c}\text { (Dependent Variable = Dispute; } \\
\text { Standard Errors in Parentheses) } \\
\text { Marginal Effects }\end{array}$} \\
\hline & 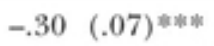 & -.50 & 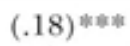 \\
\hline $\mathrm{CA}$ & $.30(.05)^{* * * *}$ & .35 & $(.07)^{* * *}$ \\
\hline FOA & $.37(.05)^{* * *}$ & .41 & $(.06) * * *$ \\
\hline CombA & $.40(.05)^{*}$ *क* & .45 & $(.05)^{*} * * *$ \\
\hline Conflict History & - & .03 & $(.02)^{*}$ \\
\hline Round & - & -.02 & $(.01)^{* *}$ \\
\hline Demographic Controls (suppressed to conserve space) & No & & Yes \\
\hline Total $\mathrm{N}=960$ (48 pairs $\times 20$ rounds $)$ & $\mathrm{N}=960$ & & $=960$ \\
\hline Restricted Log-Likelihood & -616.86 & & 32.89 \\
\hline
\end{tabular}

*Statistically significant at the .10 level; **at the .05 level; ***at the .01 level. Additional demographic control variables were all statistically insignificant (results available upon request).

\section{DISPUTANT OPTIMISM}

A key assumption in many models of arbitration outcomes is that the disputants possess identical expectations about $f(z)$, the nature of arbitrator uncertainty. Others have suggested that divergent expectations may be a cause of bargaining disagreement. Farber and Bazerman (1989) noted that divergent prior expectations of the arbitrator's notion of a fair settlement are a "prominent explanation for disagreement in bargaining" (p. 99). Their discussion originated with the idea that divergent expectations can shrink the contract zone and make agreement less likely.[17] Interestingly, the authors concluded that divergent expectations cannot by themselves explain field data results on dispute rates under CA and FOA.

Babcock and Loewenstein (1997) approached the topic of divergent expectations by exploring how a "self-serving bias" can generate bargaining disagreements. The self-serving bias results when individuals view as fair that which would benefit them more. Neale and Bazerman (1985) studied negotiator "overconfidence" in a role-playing experiment and found that overconfident negotiators were less concessionary than other negotiators. Farmer et al. (2001), using field data from Major League Baseball, found evidence that optimism - as manifested by salary offers biased away from the offer that would be predicted given known player characteristics is more prevalent for inexperienced negotiators than for negotiators with more experience. A related concept I consider is that optimism implies a self-serving "shift" in each disputant's $f(z)$ expectation (see also Pogarsky and Babcock 2001). My basic hypothesis is that such "optimism" can imply different expected payoffs under different arbitration rules, and the higher expected payoff procedures will logically be invoked more frequently. As noted before, there will be higher dispute rates for "preferred" procedures.

First, I assume fixed final offers across arbitration procedures. This assumption may be questioned, given that it is contrary to certain theoretical predictions of final offers. The data from these experiments and others I have conducted, however, are generally consistent with the assumption that average final offers are not different across arbitration procedures. Fixed final 
offers in negotiations might occur for a couple of reasons. First, individuals might demand a fixed percentage of the pie, and fixed final offers represent subjects' demanded amounts for an expected pie that is the same across treatments (see Ochs and Roth 1989). Second, disputants may view a 50-50 split of the pie as a focal point for negotiations, even though each disputant has a different perception of what $x$ should be in order to split the pie. The suggested bargaining ranges in the experiment may create divergent expectations of the pie itself, which could imply fixed final offers of $x=450$ and $x=550$ from disputants $A$ and $B$, respectively - the midpoints of the disputants' suggested bargaining ranges - if final offers are driven by this split-the-pie rule. Final offers are, on average, more divergent than this, but fixed final offers across arbitration procedures are at least consistent with such a decision rule.

Endogenous or strategic final offers would imply a more sophisticated decision rule. Brams and Merrill (1986) showed that CombA can produce convergent final offers even under (optimistically) divergent expectations. The key assumption is that each disputant is aware of his counterpart's perceived $f(z)$ distribution and bases his strategic final offer choice on the combined density function. As long as the combined $f(z)$ expectation is still unimodal, final offers converge. However, Brams and Merrill showed that if expectations diverge beyond a point, CombA will often produce a local equilibrium of divergent final offers similar to those of FOA (Brams and Merrill 1983:1351). Final offers in FOA might also be based on a combined $f(z)$ expectation, in which case Nash equilibrium final offers are still divergent - final offers would simply be a function of the combined $f(z)$ expectation. This approach to considering strategic final offers under optimistic or divergent expectations assumes that each disputant is aware of the opposing disputant's optimistic expectations and considers them in reassessing his ultimate belief about $f(z)$. If a disputant is not aware that the opposing disputant possesses different beliefs about $f(z)$, then divergent final offers are likely, though the analysis is not as clear. As such, I proceed assuming that final offers are fixed across arbitration procedures. 
Figure 2. Optimistic Beliefs (Disputant B Perspective):

$\mathrm{f}(z)$ Expected Payoffs Highest under Final Offer Arbitration.

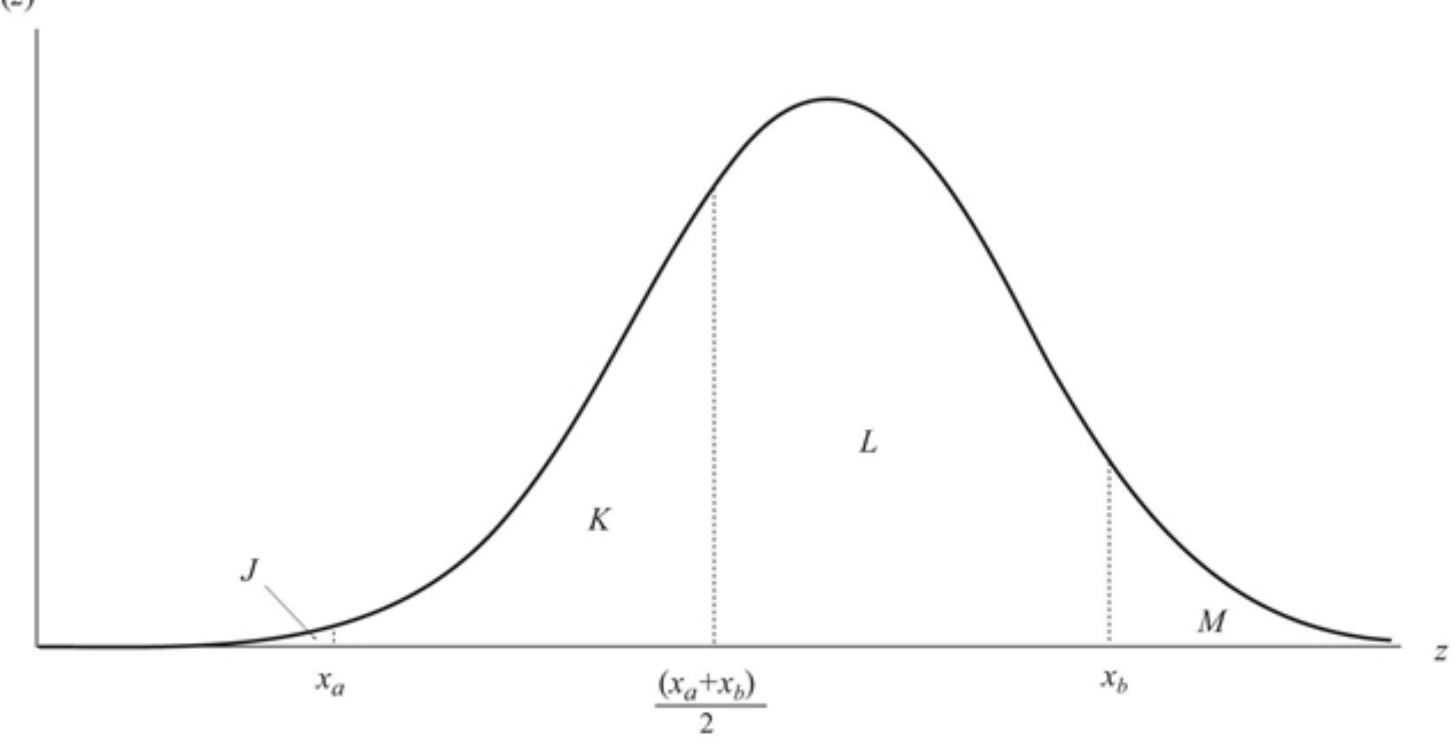

Figure 2 shows disputant B's expectation of the density function for the arbitrator's preferred settlement, z, under what I call disputant optimism. Recall that disputant B earns more for higher values of $x$, and so optimism is hypothesized to simply shift the perceived $f(z)$ distribution toward higher values of $z$. (A symmetric argument can be made for disputant A.) Therefore, in disputant $B$ 's, eyes, his final offer $x b$ is closer to the mean of $f(z)$ than is xa.[18] If expectations are viewed in this way, then one can show that, under the linear payoffs in these experiments, expected payoffs among arbitrated outcomes may be higher in FOA than in CA. The basic idea is that compared to $C A$, in which the given draw of $z$ is the arbitrated settlement for $x$, FOA would cost disputant $B$ an expected amount proportional to areas $K$ and $M$, since draws of $z$ along the horizontal axis in these areas involve lower payoff outcomes for disputant B under the FOA rules than under the $C A$ rules. Similarly, areas $\mathrm{J}$ and $\mathrm{L}$ represent gains under FOA to disputant $B$. Hence, with linear payoffs (that is, risk-neutrality), as long as $K+M<J+L$, disputant $B$ prefers FOA to CA, since the expected gains outweigh the expected losses.[19]. In general, such a distribution of optimistic expectations is guaranteed to exist for a given pair of final offers.

\section{Proof (for disputant $B$ ):}

FOA $>$ CA in terms of expected payoffs

Assume that arbitrator preferences are represented by the density function $f(z)$, which is unimodal (with mean $\mu z$ and has cumulative density function $F(z)$, and both are continuous. Assume also that disputant $B$ is optimistic so that $\mu_{z}>X_{a}+{ }_{b} / 2$ 
Then at the limit,

$$
\lim _{x_{a} \rightarrow-\infty} \mathrm{F}\left(\frac{x_{a}+x_{b}}{2}\right)-\mathrm{F}\left(x_{a}\right)=\mathrm{F}\left(\frac{x_{a}+x_{b}}{2}\right),
$$

since area $\mathrm{J}$ in Figure 2 approaches 0 as $\mathrm{x}_{\mathrm{a}} \rightarrow-\infty$. Similarly,

$$
\lim _{x_{b} \rightarrow \infty} \mathrm{F}\left(x_{b}\right)-\mathrm{F}\left(\frac{x_{a}+x_{b}}{2}\right)=1-\mathrm{F}\left(\frac{x_{a}+x_{b}}{2}\right),
$$

since area $M$ in Figure 2 approaches 0 as $x_{b} \rightarrow-\infty$. Therefore, at the limit of final offers with

$$
\mu_{z}>\frac{x_{a}+x_{b}}{2}
$$

area $\mathrm{K}+\mathrm{M}<\mathrm{L}+\mathrm{J}$, since the areas in the distribution tails become negligible. This implies that for a given distribution $f(z)$, we can always find a pair of final offers $\left(x_{a}, x_{b}\right)$ such that, with

$$
\mu_{z}>\frac{x_{a}+x_{b}}{2}
$$

we will have $K+M<L+J$. More important, this also implies that for any given pair $\left(x_{a}, x_{b}\right)$, there always exists an optimistic $f(z)$ such that $K+M<J+L$ in Figure 2. This guarantees a set of "optimistic" expectations such that FOA rules generate higher expected payoffs than CA rules. A symmetric argument can be made for disputant A-there exists an optimistic distribution $f(z)$,

$$
\left(\mu_{z}<\frac{x_{a}+x_{b}}{2}\right) \text {, }
$$

such that $\mathrm{J}+\mathrm{L}<\mathrm{K}+\mathrm{M} \cdot[20]$.

Optimistic Expectations Hypothesis: Disputes will be highest in CombA, and lowest in CA.

This ordering of dispute rates is consistent with the results reported in this paper as well as those reported in Ashenfelter et al. (1992).[21] Put plainly, the results reported in this paper are consistent with disputant optimism. Additional evidence is an observed tendency of disputants to form optimistic expectations under the experimental protocol reported in this paper. Although expectations of arbitrator behavior were not elicited for the experiments reported in this paper, I have conducted other experiments in which expectations of arbitrator behavior were elicited in CA, CombA, and FOA. The average expectations of the (computer) arbitrator's notion of a fair settlement in these experiments were $x=466$ and $x=524$ for disputant $A$ and R, respectively, a pattern consistent with disputant optimism.[22] This is an important finding given that information on arbitrator decisions was provided in the experiments in a way similar to that in which real world disputants form their expectations of arbitrator behavior (that is, based on past decisions). Also, although this argument is shown for an optimistically shaped but symmetric $f$ ( $z$ ) distribution, it will also hold under the assumption of an optimistically skewed $f(z)$. 
This argument is ad hoc, but it is a plausible theory that provides some testable implications. The data I report in this paper are consistent with this simple theory of disputant optimism, and not supportive of theories based on identical disputant expectations. In all fairness to the theoretical predictions of CombA, the concern for external validity in the experimental design (that is, presenting past draws from the preferred settlement distribution) opens the door for such asymmetries in disputant expectations. While the experimental design controls for expectations across arbitration procedures, it may not control for expectations within a bargaining pair. Therefore, it is not necessarily the case that CombA provides less incentive for agreement when subjects possess the identical expectations assumed in the theory, though such a scenario may be less externally valid.

Brams and Merrill (1986) showed that CombA theoretically generates convergence of final offers even under some considerations of asymmetric expectations, and so there is clearly room for more research to help clarify the cause of disputes and the potential role of optimism under this innovative procedure. I believe it would be useful to continue to incorporate such biased perceptions of reality into our formal theories of dispute resolution, both because such biased perceptions are well documented and because our existing theories based on unbiased expectations do not always explain the data well.

\section{CONCLUSION}

I have presented results from a controlled laboratory study of bargaining behavior under commonly used arbitration procedures as well as under an innovative procedure called combined arbitration. The mere existence of arbitration procedures to handle dispute resolution promotes their use, as is evidenced by the fact that dispute rates under all three arbitration procedures examined here exceeded the dispute rate when arbitration was absent. This result is consistent with existing research.

The results are also consistent with Ashenfelter et al. (1992) in showing significantly higher dispute rates in FOA than in CA (Table 2, basic treatment effects model). This result in itself is an important contribution to the literature, since it contradicts the common argument that FOA will reduce arbitration's chilling effect on bargaining. While Ashenfelter et al. originally generated this result, the interpretation of the finding was open to some question in their study because of their experimental environment. The results I report offer additional confirmation that the finding of higher dispute rates in FOA is robust with respect to certain details of the experimental protocol. An important policy implication is that CA is likely to produce more desirable results than FOA, since under CA disputants more often negotiate their own settlement rather than let arbitration dictate the settlement. Reports of some success in the field use of FOA may be due more to creative modifications of the FOA procedure than to what the strict rules of FOA dictate (see Feigenbaum 1975).

The data presented in this paper also provide original evidence on the comparative effectiveness of an innovative arbitration procedure, CombA, which produces a theoretical prediction of convergent final offers when disputants have common expectations and are risk- 
neutral. An expected payoff criterion also generates the prediction of lower dispute rates in CombA if disputants have unbiased expectations but are risk-averse on average. Unfortunately, dispute rates are found to be higher in CombA than in CA, and at least as high in CombA as in FOA. Additionally, the final offers submitted by disputants in CombA are not statistically significantly distinct from those in FOA.[23]

Overall, these unexpected results are consistent with the assumption that disputants form optimistic expectations of the arbitrator's notion of a fair settlement, and this optimism is stronger than any average risk aversion that experimental subjects typically display (see Holt and Laury 2002). This also implies that presenting negotiators with raw information on past arbitrator awards will likely not produce common disputant expectations of arbitrator behavior.

My future research will continue to investigate disputant optimism as a potential contributor to bargaining impasse, and also also as potential cause of differences in the likelihood of dispute across different dispute resolution procedures. The present research has, I hope, highlighted that theories based on optimism (or on divergent expectations, self-serving bias, or asymmetric information) are likely necessary for a satisfactory understanding of the likelihood of disputes in various settings.

\section{NOTES}

1. See Farber (1980), Crawford (1979), and Brams and Merrill (1983). FOA was originally suggested in Stevens (1966).

2. Brams and Merrill also suggest a modified CombA that docs not yield theoretically convergent final offers, but may involve less uncertainty for the disputants than docs the standard Comb $A$ procedure. I tested both procedures in Dickinson (2001), and the results suggested that dispute rates are significantly lower under basic CombA. For this reason, my continued investigation has focused on the standard CombA.

3. Compare, for example, Feuille (1975) and Feigenbaum (1975), who reported field data studies, and Notz, and Starke (1978) and Ashenfelter et al. (1992), who reported mock negotiations and lab data, respectively.

4. Circuit City Stores v. Adams, 99-1379.

5. Farber (1981), however, showed that what appears to be splitting-the-difference may actually be disputants strategically bracketing their final offers around the expected arbitrator award.

6. Specifically, while Ashenfelter et al. (1992) presented arbitrator information in their CA treatment by means of a table of 100 draws from the distribution used to simulate the arbitrator's notion of a fair settlement, in their FOA treatment they showed pairs of final offers along with the resultant arbitrator choice. Differences in the way subjects formed expectations under these two different information provision processes could be responsible for the differences in settlement 
rates the authors found. Indeed, if the differing information provision processes led subjects in the FOA treatment to expect lower variance in the arbitrator distribution of fair settlements than did subjects in the CA treatment — as seems likely, given that the most extreme potential settlement values in FOA are not determined by the arbitrator's notion of a fair settlement but rather by the disputants' final offers, which truncate the displayed arbitrated settlements — then the disputants' uncertainty about the arbitrator was not uncontrolled across treatments. The results of Farber and Katz (1979) are worth noting here. More uncertainty about the arbitrator's distribution of fair settlements, ceteris paribus, increases the disputants' contract/one. If uncertainty is perceived to be smaller under FOA, this will shrink the contract zone, which could lead to the higher dispute rate in FOA that Ashenfelter et al. (1992) reported.

7. The use of a mechanized arbitrator is a practical control of the bargaining environment, and it avoids potential decision-making differences between student-arbitrators and actual arbitrators (documented in Oswald 1991).

8. Pilot experiments determined that two-minute rounds were sufficient to allow subjects to negotiate a settlement if desired. This determination was based, in part, on subject comments following the pilot experiments.

9. Ashenfelter et al. (1992) similarly expressed this concern over mechanical settlements to "split the pie." They chose to make the arbitrator's mean value of the settlement distribution higher than the midpoint of the disputants' bargaining range, and they noted that this might bias their dispute rates. The feature I employ might also make disputes more likely in general. However, dispute rate comparisons across procedures are still valid.

10. Copies of the experimental instructions can be viewed at http://milo.usu.edu/ econinhr/instructions.html.

11. The chance that subjects would play a multi-round super-game was limited by withholding from them the information that five rounds of each treatment would be completed. Super-game play is still a possibility, but it is unclear how a subject might make a super-game strategy choice when it is unknown how many rounds are played before the rules of the game change. Also, to allow detection of any treatment-order effects, the specific ordering of the five-round treatment varied for different bargaining pairs. No ordering effects were found in the data. Additional analysis (available upon request) included dummy variables in the models of Table 2 to control for where initial and subsequent arbitration treatments occurred within the 20-round sequence, and arbitration round position was a statistically insignificant determinant of dispute rates $(p>.35$ in all cases).

12. This procedure was first used in Ashenfelter et al. (1992) in their CA treatment.

13. A recent example of ad hoc trial and error is the case of the online company ClickNSettle.com, which switched its online computerized mediation procedure away from a three-round model after an initial two months of (not very effective) use. 
14. Subjects were primarily freshmen and sophomores at Utah State University. Recruitment was done through classroom visits at which the experiments were described only as "economic decision-making" experiments.

15. Specifically, the probit equations in Table 2 are random effects probit estimators, since the value of inter-period, but within-pair, correlation is statistically significant $(p<.10$ for both models in Table 2).

16. For the CA/FOA comparison, the $\mathrm{x} 21$ test statistic is statistically significant in the basic treatment effects model ( $p=.04$ in the left-hand column of Table 2 ) but statistically insignificant in the right-hand column model $(p=.24)$. For the CA/CombA comparison, the difference is statistically significant for both models $(p=.02$ and $p=.09$ for the left- and right-hand models, respectively).

17. Brams and Merrill (1986) showed that under certain conditions CombA still generates convergent final offers even if disputants possess divergent expectations. The divergence they considered differs from what I hypothesize here.

18. One can also assume that optimism is a skewed $f(z)$ distribution (with more of the mass of $f$ ( $z$ ) located above the modal value of $z$ ). The entire line of reasoning in this section still follows for this distinct version of disputant optimism.

19. More precisely, for disputant B,

$$
\int_{x_{a}}^{x_{a}+x_{b} / 2}\left(z-x_{a}\right) \mathrm{f}(z) d z+\int_{x_{b}}^{\infty}\left(z-x_{b}\right) \mathrm{f}(z) d z
$$

gives the expected loss of using FOA over CA (area K + area Min Figure 2), and the expected gain is

$$
\int_{\infty}^{x_{a}}\left(x_{a}-z\right) \mathrm{f}(z) d z+\int_{x_{a}+x_{b} / 2}^{x_{b}}\left(x_{b}-z\right) \mathrm{f}(z) d z
$$

(area $\mathrm{K}+$ area $\mathrm{L}$ in Figure 2). The gains and losses are therefore directly proportional to the sixes of areas J, K, L, and M in Figure 2 when payoffs are linear.

20 The distance between the final offers, $x b-x b$, relative to the $f(z)$ variance does matter in whether optimism produces the expected payoff ordering described above. Specifically, final offers very close to each other relative to the $f(z)$ can even produce the reverse ordering of expected payoff among arbitration procedures, but the empirical data show final offers that are, on average, about 2.5 standard deviations apart (Ashenfelter et al. 1992; Dickinson 2001; and this current paper) for the specific $f(z)$ used in each case. As such, final offer data are consistent with the notion that final offers are not relatively close, and so optimism is predicted to generate the highest dispute rates in FOA. 
21 The dispute rates in CombA in this present study are, however, statistically no different from those in FOA. This is consistent with disputant optimism when area $\mathrm{J}$ of Figure 2 is only slightly larger than area $\mathrm{M}$ (that is, disputants perceive the $\mathrm{f}(\mathrm{z})$ tails as fatter for more personally preferable settlements, but most of the optimism is around the high probability median of the distribution).

22 The reported expectations numbers are based on my continued research and are average expectations from thirty bargaining pairs.

23 This result, in and of itself, may imply that not much information is gained from the table of 100 draws from $f(z)$. This is not inconsistent with disputants then forming their own optimistic expectation of what the actual arbitrator notion of a fair settlement will be. I plan future experiments to control more directly for subject expectations in order to conduct pure tests of the theory.

\section{REFERENCES}

Ashenfelter, Orley. 1987. "A Model of Arbitrator Behavior." American Economic Review, Vol.77, No. 2 (May), pp. 342-46.

Ashenfelter, Orley, and David Bloom. 1984. "Models of Arbitrator Behavior: Theory and Evidence." American Economic Review, Vol. 74, No. 1 (March), pp. 111-24.

Ashenfelter, Orley, Janet Currie, Henry S. Farber, and Matthew Spiegel. 1992. "An Experimental Comparison of Dispute Rates in Alternative Arbitration Systems." Econometrica, Vol. 60, No. 6 (November), pp. 1407-33.

Babcock, Linda, and George Loewenstein. 1997. "Explaining Bargaining Impasse: The Role of Self- Serving Biases." Journal of Economic Perspectives, Vol. 11, No. 1 (Winter), pp. 109-26.

Babcock, Linda, George Loewenstein, and Xianghong Wang. 1995. "The Relationship between Uncertainty, the Contract Zone, and Efficiency in a Bargaining Experiment." Journal of Economic Behavior and Organization, Vol. 27, No. 3, pp. 475-85.

Bolton, Gary E., and Elena Katok. 1998. "Reinterpreting Arbitration's Narcotic Effect: An Experimental Study of Learning in Repeated Bargaining." Games and Economic Behavior, Vol. 25, No. 1, pp. 1-33.

Brams, Steven J, and Samuel Merrill, III. 1983. "Equilibrium Strategies for Final-Offer Arbitration: There Is No Median Convergence." Management Science, Vol. 29, No. 8, pp. 92741.

1986. "Binding Versus Final-Offer Arbitration: A Combination Is Best." Management Science, Vol. 32, No. 10, pp. 1346-55. 
Crawford, Vincent. 1979. "On Compulsory Arbitration Schemes." Journal of Political Economy, Vol. 87, No. 1 (February), pp. 131-60.

Currie, Janet, and Shccna McConnell. 1991. "Collective Bargaining in the Public Sector: The Effect of Legal Structure on Dispute Costs and Wages." American Economic Review, Vol. 81, No. 4 (September), pp. 693-718.

Dickinson, David L. 2001. "Dispute Resolution with 'Combined' Arbitration." Utah State University ERI paper \#2001-02.

Farber, Henry S. 1980. "An Analysis of Final-Offer Arbitration." Journal of Conflict Resolution, Vol. 24, No. 4, pp. 683-705.

----. 1981. "Splitting the Difference in Interest Arbitration." Industrial and Labor Relations Review, Vol. 35, No. 1 (October), pp. 70-77.

Farber, Henry S., and Max H. Bazerman. 1989. "Divergent Expectations as a Cause of Disagreement in Bargaining: Evidence from a Comparison of Arbitration Schemes." Quarterly Journal of Economics, Vol. 104, No. 1 (February), pp. 99-120.

Farber, Henry S., and Harry C. Katz. 1979. "Interest Arbitration, Outcomes, and the Incentive to Bargain." Industrial and Labor Relations Review, Vol. 33, No. 1 (October), pp. 55-63.

Farmer, Amy, Paul Pecorino, and Victor Stango. 2001. "Asymmetric Information and Excessive Optimism as Causes of Bargaining Failure: Evidence from Major League Baseball." Working paper \#00-08-04, University of Alabama.

Feigenbaum, Charles. 1975. "Final Offer Arbitration: Better Theory Than Practice." Industrial Relations, Vol. 14, No. 3 (November), pp. 311-17.

Feuille, Peter. 1975. "Final Offer Arbitration and the Chilling Effect." Industrial Relations, Vol. 14, No. 3 (November), pp. 302-10.

Grigsby, David W, and William J. Bigoness. 1982. "Effects of Mediation and Alternative Forms of Arbitration on Bargaining Behavior: A Laboratory Study." Journal of Applied Psychology, Vol. 67, No. 5 (October), pp.549-54.

Heckman, James. 1979. "Sample Selection Bias as a Specification Error." Econometrica, Vol. 47, No. 1 (January), pp. 153-61.

Holt, Charles A., and Susan K. Laury. 2002 "Risk Aversion and Incentive Effects." American Economic Review, Vol. 92, No. 5 (December), pp. 1644-55.

Neale, Margaret, and Max Bazerman. 1983. "The Role of Perspective Taking Ability in Negotiating under Different Forms of Arbitration." Industrial and Labor Relations Review, Vol. 36, No. 3 (April), pp. 378-88.

-----. 1985. "The Effects of Framing and Negotiator Overconfidence on Bargaining Behaviors and Outcomes." Academy of Management Journal, Vol. 28, No. 1 (March), pp. 34-49. 
Notz, William W., and Frederick A. Starke. 1978. "Final Offer Versus Conventional Arbitration as Means of Conflict Management." Administrative Science Quarterly, Vol. 23, No. 2 (June), pp. 189-203.

Ochs, Jack, and Alvin E. Roth. 1989. "An Experimental Study of Sequential Bargaining." American Economic Review, Vol. 79, No. 3 (June), pp. 355-84.

Oswald, Sharon L. 1991. "Students as Arbitrators: An Empirical Investigation." Industrial Relations, Vol. 30, No. 2 (Spring), pp. 286-93.

Pogarsky, Greg, and Linda Babcock. 2001. "Damage Caps, Motivated Anchoring, and Bargaining Impasse." Journal of Legal Studies, Vol. 30, No. 1 (January), pp. 143-59.

Roth, Alvin E. 1995. "Bargaining Experiments." In John H. Kagel and Alvin Roth, eds., The Handbook of Experimental Economics. Princeton: Princeton University Press.

Stevens, Carl M. 1966. "Is Compulsory Arbitration Compatible with Bargaining?" Industrial Relations, Vol. 5, No. 1 (Winter), pp. 38-52.

Walton, Richard E., and Robert B. McKersie. 1965. A Behavioral Theory of Labor Negotiations. New York: McCraw-Hill. 